\title{
Perception of Women on Gender-Based Violence in Guinea: A Qualitative Study
}

\section{Mamadou Dioulde Balde ${ }^{1}$, Ramata Diallo ${ }^{1}$, Amadou Oury Toure ${ }^{1}$, Alpha Oumar Sall ${ }^{1}$, Anne Marie Soumah $^{1}$, Aissatou Diallo ${ }^{1}$, Sadan Camara ${ }^{1}$, Bienvenu Salim Camara ${ }^{2}$ and Boubacar Alpha Diallo ${ }^{3}$}

${ }^{1}$ Center for Research in Reproductive Health in Guinea (CERREGUI), Conakry, Guinea

${ }^{2}$ National Center for Training and Research in Rural Health, Maferinyah, Guinea

${ }^{3}$ Department of Obstetrics and Gynecology, Teaching Hospital Donka, Conakry, Guinea

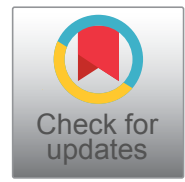

*Corresponding author: Mamadou Dioulde Balde, Center for Research in Reproductive Health in Guinea (CERREGUI), BP 4880 Conakry, Guinea, Tel: (00224)-628213340

\begin{abstract}
Background: Gender-based violence exists and is increasing worldwide, with higher rates in African regions where gender inequality persists. It affects adolescent girls and adult women. In Guinea, violence against women is a widespread phenomenon. Indeed, 9 out of 10 women aged from 15 to 64 have been victim of at least one act of violence. The objective of this study is to explore the perceptions of women in the community about the violence that they have undergone.
\end{abstract}

Methods: It is a qualitative study using focus group discussions (FGD) with women aged 15-49 in three health districts.

Results: Of the 18 FGD conducted, young women aged 20 to 24 were the most represented (33\%). The main types of Gender-based violence include physical violence, sexual violence (rape) and verbal violence. These types of violence are committed by husbands and boyfriends as well as parents of young girls in a context of forced marriage. The consequences of this violence are injuries, unwanted pregnancies, induced abortions, woman humiliation, depression, divorce and abandonment of the children by the husbands. Women's attitudes to this violence are essentially to remain silent for fear to be stigmatized, health care seeking and filing complaints to the gendarmerie/police or to the leaders of district and notables.

Conclusion: GBV is recurrent in Guinea in all its forms. The perpetrators are intimate partners, family members and unknown aggressors. This phenomenon requires sustained attention of the authorities and a commitment of all the stakeholders in order to highlight the problem and make advocation for women so that these acts of violence can be reduced.

\section{Keywords}

Gender-based violence, Perceptions, Intimate partners, Physical violence, Sexual violence, Guinea

\section{Abbreviations}

DHS: Demographic and Health Survey; FGD: Focus Group Discussion; FGM: Female Genital Mutilation; GBV: Gender Based Violence; HRP: Health Reproductive Program; IPV: Intimate Partner Violence; WHO: World Health Organization

\section{Background}

The GBV phenomenon is universal. According to the WHO global estimates, 35\% (approximately one third) of women, report to have been exposed to physical or sexual violence in their life, by an intimate partner or someone else. The WHO regions of Africa and the Eastern Mediterranean are most affected by this phenomenon, with a prevalence of $33 \%$ [1]. In fact, intimate partner violence refers to any behavior within an intimate relationship (partner or ex-partner) that causes physical, sexual or psychological harm, including physical aggression, coercive sex, psychological violence and other forms of domination [1].

The GBV is a problem that reflects the unequal power dynamics created in the gender binary system and is often perpetrated by those with more physical, cultural or social power and inflicted on those without [2]. It is prevalent among adolescent girls and young

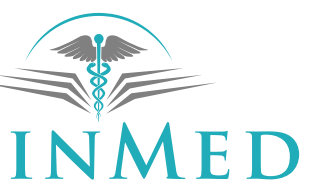

INTERNATIONAL LIBRARY

Citation: Balde MD, Diallo R, Toure AO, Sall AO, Soumah AM, et al. (2022) Perception of Women on Gender-Based Violence in Guinea: A Qualitative Study. Int J Womens Health Wellness 8:136. doi. org/10.23937/2474-1353/1510136

Accepted: February 18, 2022: Published: February 20, 2022

Copyright: (c) 2022 Balde MD, et al. This is an open-access article distributed under the terms of the Creative Commons Attribution License, which permits unrestricted use, distribution, and reproduction in any medium, provided the original author and source are credited. 
adult women of low- and middle-income countries. Indeed, $28 \%$ of adolescent girls and $29 \%$ of young adult women reported to have experienced physical or sexual violence in their life, with the highest prevalence in the Eastern and Southern African region according to a quantitative study derived from the Demographic Health Survey (DHS) [3].

Violence against women is a widespread phenomenon in Guinea. Indeed, the results of a survey conducted in 2009 revealed a prevalence of $91.9 \%$ of GBV, at least $9 / 10$ women aged from 15 to 64 have been victims of an act of violence since the age of 15 . Among these, $36.5 \%$ were victims during the last 12 months preceding the survey [4]. Furthermore, at the age of 15 years, $24 \%$ of the girls live in a couple, this early marriage is a factor contributing to GBV in Guinea.

Another national survey conducted in 2016 on GBV reported that $55.7 \%$ of women reported to be victims of physical violence and $29.3 \%$ of sexual violence [5]. Guinean legislation stipulates laws against all forms of gender-based violence, but due to the ignorance of these laws, the economic vulnerability including sociocultural factors (religion, customs), victims' recourse is restricted. A training program for providers on the management of GBV has been developed, but it has not been widely distributed [5]. This is why it is important to understand this topic in order to get the opinions of women in the community on the violence perpetrated against them. It was noted that female genital mutilation (FGM), another form of GBV which is deeply rooted in Guinea (95\% of women aged 15-49 have undergone FGM/Cutting), will not be included in this study due to its scope, associated factors and specific characteristics $[6,7]$.

\section{Objective of the Study}

To explore perceptions and attitudes of women in the community towards GBV.

\section{Specific objectives}

- Determine the magnitude of GBV

- To identify the types of violence experienced by women

- To determine the consequences of violence for women's health

- To describe women's attitudes towards GBV

\section{Study setting}

The Republic of Guinea is a coastal country in the West African region, covering an area of $245,857 \mathrm{~km}^{2}$, with a population estimated at 12,877,894 in 2021 . It is comprised of four natural regions, and eight administrative regions including the capital Conakry. The majority of the Guinean population is strongly influenced by gender biases and stereotypes that assign social positions to men and women. This perception of male-female relations establishes a real supremacy of the first over the second. Under the leadership of the Ministry of Social Action, Promotion of Women and Children, true progress has been made with the support of technical and financial partners, to fight against all forms of GBV. Legislative and regulatory texts have been adopted, and new institutions have been created or strengthened, such as the Office for the Protection of Gender, Childhood and Morals [5].

\section{Methods}

This is a cross-sectional qualitative study of women aged from 15 to 49 years in the community.

\section{Study sites}

To guarantee national representativeness on this issue, which is strongly customs-based, the prefectures of Mamou, Dabola and Lola, located in the different natural regions of Guinea, were targeted for this study.

\section{Sampling}

A random draw was carried out to select one urban and rural area per prefecture. The selection of FGD participants was done with the help of a local community guide and with the support of local women's association leaders.

\section{Data collection techniques}

Eighteen FGDs were equally conducted between urban and rural areas from September to October 2014. To conduct FGDs, Interviewers and supervisors received training on the use of the FGD guide for this study (magnitude, types, health consequences, women's attitudes).

\section{Data analysis}

The strategic assessment technique developed by the WHO/HRP with the use of similarity and difference tables was used to analyze the data collected in the field [8].

\section{Ethical considerations}

The National Health Research Ethics Committee of Guinea validated the study protocol. The procedure for obtaining informed consent from participants was followed throughout the data collection. Confidentiality of the information collected was ensured during and after the study.

\section{Results}

Table 1 shows that adolescent girls aged from 15 to 19 years constitute more than a quarter $(26 \%)$ of the study population and young women in the age group of $20-24$ years represent $33 \%$ of it. Among them, $64.9 \%$ were married; $29.2 \%$ were housewives and almost half (49.4\%) had no schooling. 
Table 1: Socio-demographic characteristics of FGD participants.

\begin{tabular}{|c|c|c|c|c|c|c|}
\hline & Urban $\mathbf{N}=83$ & $\%$ & Rural N = 73 & $\%$ & Total $N=154$ & $\%$ \\
\hline \multicolumn{7}{|c|}{ Age } \\
\hline 15-19 Years & 16 & 19.8 & 24 & 32.9 & 40 & 26.0 \\
\hline $20-24$ & 28 & 34.6 & 23 & 31.5 & 51 & 33.1 \\
\hline $25-30$ & 18 & 22.2 & 13 & 17.8 & 31 & 20.1 \\
\hline $31-35$ & 2 & 2.5 & 3 & 4.1 & 5 & 3.2 \\
\hline $36-40$ & 4 & 4.9 & 7 & 9.6 & 11 & 7.1 \\
\hline $41-45$ & 13 & 16.0 & 3 & 4.1 & 16 & 10.4 \\
\hline Total & 81 & 100 & 73 & 100 & 154 & 100 \\
\hline \multicolumn{7}{|c|}{ Educational level } \\
\hline Any & 36 & 44.4 & 40 & 54.8 & 76 & 49.4 \\
\hline Primary & 17 & 21.0 & 14 & 19.2 & 31 & 20.1 \\
\hline Secondary & 21 & 25.9 & 17 & 23.3 & 38 & 24.7 \\
\hline Professional & 3 & 3.7 & 0 & 0 & 3 & 1.9 \\
\hline Superior & 4 & 4.9 & 2 & 2.7 & 6 & 3.9 \\
\hline Total & 81 & 100 & 73 & 100 & 154 & 100 \\
\hline \multicolumn{7}{|c|}{ Occupation } \\
\hline Housewife & 15 & 18.5 & 30 & 41.1 & 45 & 29.2 \\
\hline Pupil/Student & 15 & 18.5 & 16 & 21.9 & 31 & 20.1 \\
\hline Dressmaker & 13 & 16.0 & 10 & 13.7 & 23 & 14.9 \\
\hline Trader & 11 & 13.6 & 9 & 12.3 & 20 & 13.0 \\
\hline Cultivator & 9 & 11.1 & 3 & 4.1 & 12 & 7.8 \\
\hline Teacher/Health worker & 6 & 7.4 & 1 & 1.4 & 7 & 4.5 \\
\hline Hairdresser & 5 & 6.2 & 1 & 1.4 & 6 & 3.9 \\
\hline Others & 7 & 8.6 & 3 & 4.1 & 10 & 6.5 \\
\hline Total & 81 & 100 & 73 & 100 & 154 & 100 \\
\hline \multicolumn{7}{|c|}{ Marital status } \\
\hline Unmarried & 27 & 33.3 & 24 & 32.9 & 51 & 33.1 \\
\hline Married & 52 & 64.2 & 48 & 65.8 & 100 & 64.9 \\
\hline Widowed & 1 & 1.2 & 0 & 0 & 1 & 0.6 \\
\hline Divorced & 1 & 1.2 & 1 & 1.4 & 2 & 1.3 \\
\hline Total & 81 & 100 & 73 & & 154 & 100 \\
\hline \multicolumn{7}{|c|}{ Number of living children } \\
\hline $0-2$ & 52 & 64.2 & 55 & 75.3 & 107 & 69.5 \\
\hline $3-5$ & 20 & 24.7 & 16 & 21.9 & 36 & 23.4 \\
\hline 6 et plus & 9 & 11.1 & 2 & 2.7 & 11 & 7.1 \\
\hline Total & 81 & 100 & 73 & 100 & 154 & 100 \\
\hline
\end{tabular}

\section{Types/Forms of GBV}

As illustrated by the following statements, physical (beatings), sexual and verbal violence as well as forced marriages were reported as the main types of GBV experienced by women in their community. For example, a young participant from an urban area confirmed:

"I have a cousin who is unhappy at home. Her husband always beats her for; he does not like her very much. He sometimes beats or insults her in front of the neighborhoods. It's a situation that worries the whole family".
Insults are also very frequent, especially in households. "In our community, women are victim of all kinds of violence. We are insulted by our husbands. We are marginalized in decisions that concern our children. We are wronged in the sharing of inheritances. We are also beaten and hurt by our husbands and their brothers. It is really pitiful to be a woman in this context."

Concerning sexual violence perpetrated by husbands or sometimes by some young men in the neighborhood. A young woman living in a rural area report: "Last time 
a girl was raped at home by her cousin in our district. The young man took advantage on the long absence of the mother, who was on a trip to Dabola. And the girl's brothers were at school."

Sexual and intimate violence is common in households with the previous of forced and often early marriage. A young woman in a rural area explains that:

"When a girl is married by force, most often there is fight in the home. Her husband often beats her because she has no love for him and he wants to force her to have sex."

Concerning forced marriages, a participant from an urban area insists on the full responsibility of parents in the GBV: "Yes, we have cases of forced marriages. A 15-year-old girl was forced to marry an adult man that she did not want. The man with whom she wanted to get married was the father of one her friends, you see? She was obliged to get married to a man that she didn't love. This act can traumatize her during all her lifetime. This girl's parents deprived her of everything. We can say that she was a victim of violence by her own parents."

\section{GBV perpetrators}

Most of the participants said that husbands are the main perpetrators of GBV. Husbands are very violent and use every argument to hurt their wives, as reported by a 28-year-old woman in an urban area: "We are much mistreated by our husbands. I myself have just been sent back to my parents because one day, being ill, I couldn't work in the household. So when my husband arrived, there was no food. He didn't ask. He made me leave the house with a slap. I had to sleep at the neighbors. In the morning he looked for a vehicle, put all my belongings in and sent me to my parents."

Sometimes it is the husband's younger brother who comes to beat the wife, as reported by this rural 40-year-old woman: "Of course, violence exists here. Let me tell you that my husband's younger brother came to beat me at home because of his sister who lives with us. When I told my husband what his brother did to me, he took his brother's share again. On top of that, he insulted me like a child. I didn't have means than leaving my own fight to God."

But in addition, mainly girls' boyfriends are strongly accused of acts of physical violence that can lead to injuries. A young participant from an urban center explains: "Here, many girls are victim of beatings and injuries from their boyfriends, who are sometimes very demanding, as if they were their husbands. It's really difficult when the person you trust hurts you too much."

According to a participant from an urban area, it is very risky to walk around at night in some neighborhoods because the possibility of being assaulted by young people under drugs.
"There are corners in the city here where you don't dare to go alone there at late hours otherwise the young people gather to smoke, as soon as a girl goes there alone, they go and rape her."

The parents can perpetrate physical and psychological violence against girls in a context of early and forced marriage. A woman from urban center reports:

"I am not saying that violence against women does not exist here, but it is not too widespread. The cases I have seen are that, the parents of a young girl who was only 12-years-old decided to give her to marriage but the girl didn't want at all. I saw her father who tied her up and beat her badly until her whole body became a mess. Under the pretext that she wants to dishonor him."

\section{Consequences of GBV}

There are many consequences. For example, rape can lead to unwanted pregnancies. This can lead to induced abortions. A young student from a school explains: "The consequences of violence are numerous. There are pregnant women who commit abortions or give birth prematurely when they are beaten and they are too stressed. We also have cases of induced abortions because of shame. Because if a girl who is victim of rape is unlucky enough to get pregnant, she will try to abort the pregnancy. This puts her life at risk. Afterwards, she may not be able to have a child anymore."

Furthermore, in the case of a pregnancy resulting from rape, the perpetrators often refuse to acknowledge paternity; this leads to the humiliation of the woman and her family. A young woman from a rural area report: "Girls who are raped by their boyfriends end up with unwanted pregnancies that the boyfriends refuse to recognize. So you will see that she is shunned in her own family and even in her surroundings."

A young woman living in an urban area also insists on this shaming of women: "Talking about the consequences of rape, there are many unwanted pregnancies here that lead to abortions with all the problems. There are girls who are not married that get pregnant. They will no longer have any respect in their family and even in their surroundings."

Pregnancies resulting from rape are sometimes accompanied by depression of the victim. A young woman in an urban area report: "Women who are victim of violence or rape are often depressed. Others are so ashamed that they find it difficult to go out in the community. Some of them prefer to move to another neighborhood because of the stigma."

Participants in the FGDs also reported that physical violence sometimes leads to injuries and even fractured limbs in female victims, as this 25 -year-old girl reports: "We women are forced to follow what our parents tell us. I have got an older sister who ran away from her 
husband who almost killed her. She says that he requires sex every day, morning and night. Then, the day she refuses, he beats her. One day he broke her arm and then apologized. My sister has decided never love him anymore even if we have to kill her. She said that she won't go back to her husband."

Divorce is another consequence of domestic violence cited in several FGDs. For example, a young married girl in a rural area explains: "I left my first husband because of this. Every time he used to insult and beat me, especially on the day he was drunk. And that day, I would not have peace of mind. I did everything I could but I realized that I would always have problem him. I went one day to tell my parents that I could no longer stay with him. Fortunately, I did not have a child with him."

These separations as a result of domestic violence can lead to the husband abandoning his children. A 25-year-old woman from an urban area explains:

"Violence has more consequences. Especially if it leads to divorce. I am telling you this because I divorced my first husband. But I know that it caused difficulties in the education of my children. You know that men, when they abandon a woman, do the same thing to the children and this has a direct impact on their education."

\section{Attitudes towards GBV}

As for the attitude of women and their families towards GBV, the first one is silence, followed by the care and the steps to take after the violence. Because of the fear of parents' reactions or stigmatization in the community, girls who have been raped are sometimes forced to remain silent, as these urban adolescents explain:

"The problem is that some girls, when they are raped, do not dare to talk to their family members or friends because they are ashamed or they fear discrimination. The pregnancy is discovered when they start to get sick and the family sends them to the hospital."

This silence is also observed among married women in domestic violence cases for discretionary reasons: "We try to talk about it as a family, but sometimes we keep quiet. Otherwise, everyone will say that you filed a complaint against your husband with the authorities. You won't be welcome in the community. If you divorce, you won't find a husband because people will label you as a woman who doesn't respect men"

In addition, women victim of physical violence go to local health facilities (hospitals, health centers) for treatment, especially in case of injuries or fractures.

"We go to the hospital for treatment of violence, and the injuries are treated. But you know that scars and after-effects can remain on the victim...."

In the case of legal proceedings, the complaints of the families of victims of physical and sexual violence (including rape) are mainly addressed to the gendarmerie and the police: "In cases of rape of young girls on the first day, we often start with the hospital to treat the girl. Then the family of the perpetrator is summoned to the gendarmerie".

Complaints are also filed with the neighborhood leaders and the family of the perpetrator of the rape or physical violence (assault and battery). The following quotes speak for themselves:

"In our community, the victims' families most often turn to the rapist's family if he has been identified by the girl. If there is no agreement, the complainants turn to the gendarmerie or other security services."

"When there are fights between girls and their boyfriends, the girl's parents go to the boy's family, to the authorities such as the police. If there are injuries, the girl is taken to hospital for a check-up and treatment."

In cases of domestic violence, mediation within the family or with community leaders is prioritized.

"When there is a problem between a husband and his wife, the woman goes first to her in-laws to talk about it and if they do not manage to resolve it, she goes to her parents' house".

"The women victim of violence also turns to the local notables and imams in the hope that they will be able to sensitize their husbands and bring them to quit violence".

\section{Discussions}

Gender-based violence is a widespread phenomenon in Guinea. It is observed in many countries around the world, to various extents. Indeed, women are constantly exposed to threats of violence, especially domestic violence [9-11].

The main forms of violence against women observed in our study are physical violence in the form of beatings, sexual violence (including rape) and verbal violence as well. The same observation has been made by several authors. In Ghana and Brazil, sexual violence was also accompanied by physical and psychological violence $[12,13]$. Also in Nigeria, physical violence was the most common type experienced by women (58.1\%) [14]. In another school-based study in Ethiopia, sexual violence and physical violence were $37.2 \%$ and $56.3 \%$ respectively [15]. In addition, other authors have reported harassment $[16,17]$. A systematic review in sub-Saharan Africa also reveals other forms including emotional violence (29.40\%) [18]. A study in Pakistan also reports other types of violence against women in the community besides physical and verbal violence, including controlling behavior of the husband, conflicts with in-laws, overload of domestic work and the threat to leave or remarry [19]. 
The Perpetrators of $G B V$ in Guinea is often perpetrated in households by women's husbands, in neighborhoods by girls' boyfriends and also at family level, by the parents of young girls in cases of forced marriage. The perpetrators of violence against women are described differently in other studies on GBV, depending on the circumstances in which they occur. For example, women's intimate partners are often cited in cases of sexual violence [10,20-22]. Perpetrators can also be unknown aggressors $[10,13]$, as in our study, or known aggressors in the community [10]. Alcohol abuse has been cited in our study and by other authors as a factor contributing to the occurrence of physical and sexual violence $[15,16,22-26]$. In Northern Macedonia, other major risk factors have been identified, such as the perpetrator's poor economic status, low level of education, unemployment, male privilege and the woman's subordinate status [23].

Consequences of $G B V$ are multiples. According to our data, rape can lead to unwanted pregnancies, resulting in a high rate of induced abortions and the humiliation of women and their families. In addition, there are cases of depression of the victim woman. Our study also revealed that physical violence often leads to injuries, including broken limbs. Divorce and abandonment of children by the husband are others consequences of domestic violence. These different effects have also been reported by other authors, such the risk of induced abortion [27]. As in our study, female victims of GBV are also stigmatized in the Caribbean and in Pakistan $[2,19]$. The same applies to feelings of shame and guilt, which often prevent victims from seeking help from health professionals [2,19]. In Ghana, women have suffered physical injuries, psychological problems, sexual and reproductive health problems and suicidal thoughts as a result of violence [12]. These health problems have significantly affected their economic activities and impoverished their income. Sexual violence thus clearly interferes with women's empowerment [12].

\section{Women's attitudes towards GBV}

This study reveals that girls who have been raped often remain silent for fear of their parents or of stigmatization in the community. This phenomenon was also highlighted among women who married to save their homes. Physical violence is treated in health facilities. Families of victims of physical and sexual violence (including rape) file complaints with the security services, but also with neighborhood leaders and the family of the perpetrator of the rape or other physical violence. In the case of domestic violence, mediation within the family or with community leaders is the preferred option. In terms of GBV management, other authors highlight the limited availability of health services for GBV and the low use of these services like in Tanzania [28]. Many studies have noted, as in our results, the silence of married women, which is the result of their "acceptance" of domestic violence. Indeed, the 2018 Guinea DHS reported that 48\% of women think it is justified for a man to beat his wife if she refuses to have sexual intercourse with him and $54 \%$ when the woman goes out without her spouse's permission [6]. The prevalence of acceptance of intimate partner violence (IPV) is lower in Benin with 15.7\% [29].

Studies conducted in Ethiopia also show that intimate partner violence is accepted in the community in case of infidelity [11,30]. For some women, GBV should be tolerated rather than condemned [11]. According to some authors, most women remain silent and very few defend themselves against violent husbands/partners $[11,30]$. The reason for women's silence is that they fear that the violence will intensify if they report it, and they fear the social stigma as well as the impact of the violence on the children $[2,19]$.

\section{Strengths and limitations}

This study explored women's perceptions of violence against them, focusing on the forms and consequences of GBV and the attitudes they adopt when they are victims. However, the lack of data on the causes and associated factors is a limiting factor of this study. Furthermore, the collection of men's opinions on GBV would have allowed us to better grasp the issue.

\section{Implications for practice and future research}

The results of this study could be used to develop programs to fight and prevent GBV. In order to strengthen the prevention and fight against GBV in Guinea, it would be important to conduct studies in the future, including a quantitative component that would analyze the causes and factors that contribute to the occurrence of violence against women. This research should also reach out to men in the community and other stakeholders (health care providers, security and judicial services workers).

\section{Conclusion}

The GBV in all its forms is significant in Guinea. It is perpetrated by intimate partners, family members or unknown aggressors. Women often choose to remain silent in order to avoid other harmful consequences. This phenomenon should call for sustained community commitment through actions that will make everyone aware of their rights and duties. It also requires special attention from the authorities with the collaboration of all stakeholders through awareness and the adoption and enforcement of laws to fight against the phenomenon until its eradication.

\section{Source of Funding}

This article is a secondary analysis of data from a research study on "Women's Health in Guinea. Situational analysis" which is funded by WHO with MUSKOKA funds in 2014. 


\section{No Conflict of Interest}

The authors declare that they have no competing interests.

\section{Availability of Data and Materials}

Data set will be made available upon request.

\section{Authors' Contributions}

Study Design: MDB, AOS; Data collection: RD, AOT, AMS, SD, AD; Manuscript writing: MDB, RD, AOT, AOS, $S D, A D, B S C, A B D ;$ Review and editing: All authors.

\section{References}

1. World Health Organization (2018) Violence against women prevalence estimates, 2018: Global, regional and national prevalence estimates for intimate partner violence against women and global and regional prevalence estimates for non-partner sexual violence against women: Executive summary.

2. Tsapalas D, Parker M, Ferrer L, Bernales M (2021) GenderBased violence, perspectives in Latin America and the Caribbean. Hispanic Health Care International 19: 23-37.

3. Decker MR, Latimore AD, Yasutake S, Haviland M, Ahmed S, et al. (2015) Gender-Based violence against adolescent and young adult women in low- and middle-income countries. Journal of Adolescent Health 56: 188-196.

4. Keita ML (2009) National Survey on Gender-Based Violence. Violence against women and men 2009. Technical support office for studies and research.

5. (2017) Enquête nationale sur les violences basées sur le genre en Guinée.

6. Institut National de la Statistique (INS), ICF (2018) Demographic and Health Survey in Guinea 2018. Conakry, Guinea and Rockville, Maryland, USA.

7. Balde MD, O'Neill S, Sall AO, Balde MB, Soumah AM, et al. (2021) Attitudes of health care providers regarding female genital mutilation and its medicalization in Guinea. PLoS One 16: e0249998.

8. World Health Organization (2007) The WHO strategic approach to strengthening sexual and reproductive health policies and programmes.

9. Kassa GM, Abajobir AA (2018) Prevalence of violence against women in Ethiopia: A meta- analysis. Trauma Violence Abuse 21: 624-637.

10. Thulin EJ, Lustig A, Perrotte V, Lwabanya M, Evans T (2020) Male and female perceptions and experiences of sexual and gender-based violence in South Kivu, Eastern DRC. J Interpers Violence 1-27.

11. Muche AA, Adekunle AO, Arowojolu AO (2017) GenderBased violence among married women in debre tabor town, Northwest Ethiopia: A qualitative study. Afr J Reprod Health 21: 102.

12. Apatinga GA, Tenkorang EY, Issahaku $P$ (2020) Silent and lethal: Consequences of sexual violence against married women in Ghana. J Interpers Violence 36: 1-23.

13. Cruz MS, Guilherme Irffi (2019) What is the effect of violence against Brazilian women on their self-perception of health? Ciência \& Saúde Coletiva 24: 2531-2542.

14. Adinma JIB, Oguaka VN, Ugbaja JO, Umeononihu OS, Adinma-Obiajulu ND, et al. (2019) Experience of, and Perception on Gender Based Violence (GBV) by Pregnant Women in South Eastern Nigeria. Advances in Reproductive Sciences 7: 113-124.
15. Tantu T, Wolka S, Gunta M, Teshomev M, Mohammed H, et al. (2020) Prevalence and determinants of gender based violence among high school female students in Wolaita Sodo, Ethiopia: An institutionally based cross-sectional study. BMC Public Health 20: 540.

16. Kaufman MR, Williams AM, Grilo G, Marea CX, Fentaye FW, et al. (2019) We are responsible for the violence, and prevention is up to us": a qualitative study of perceived risk factors for gender-based violence among Ethiopian university students. BMC Women's Health 19: 131.

17. Osuna-Rodríguez M, Rodríguez-Osuna LM, Dios I, Amor MI (2020) Perception of Gender-Based Violence and Sexual Harassment in University Students: Analysis of the Information Sources and Risk within a Relationship. Int J Environ Res Public Health 17: 3754.

18. Muluneh MD, Stulz V, Francis L, Agho K (2020) Gender based violence against women in sub-saharan africa: $A$ systematic review and meta-analysis of cross- sectional studies. Int J Environ Res Public Health 17: 903.

19. Madhani FI, Karmaliani R, Patel C, Bann CM, McClure EM, et al. (2017 Women's perceptions and experiences of domestic violence: An observational study from Hyderabad, Pakistan. J Interpers Violence 32: 76-100.

20. Yount KM, Krause KH, Miedema SS (2017) Preventing gender-based violence victimization in adolescent girls in lower-income countries: Systematic review of reviews. Soc Sci Med 192: 1-13.

21. Chernet AG, Cherie KT (2020) Prevalence of intimate partner violence against women and associated factors in Ethiopia. BMC Women's Health 20: 22.

22. Bhattacharjee $P$, Huiting $M$, Musyoki $H$, Cheuk E, Isac $S$, et al. (2020) Prevalence and patterns of gender-based violence across adolescent girls and young women in Mombasa, Kenya. BMC Women's Health 20: 229.

23. Tozija F (2020) Women's Safety and Gender-Based Violence in the Republic of North Macedonia. Front Public Health 8: 33.

24. Waterman EA, Edwards KM, Makoni El, Siller L, Murphy SB, et al. (2020) Zimbabwean stakeholders' perspectives on causes of and solutions to gender-based violence in their community: Findings from a focus group. Violence Against Women 27: 973-984.

25. Wood EA, Wilson KE, Jacobs KD (2021) Exploring the differences between men's and women's perceptions of gender-based violence in rural Tajikistan: A qualitative study. BMC Women's Health 21: 91.

26. Iyanda AE, Boakye KA, Olowofeso OH, Lu Y, Salcido Giles $\mathrm{J}$ (2019) Determinants of gender-based violence and its physiological effects among women in 12 African Countries. $\mathrm{J}$ Interpers Violence 36: 1-24.

27. McCloskey LA (2016) The effects of gender-based violence on women's unwanted pregnancy and abortion. Yale J Biol Med 89: 153-159.

28. Mtaita C, Likindikoki S, McGowan M, Mpembeni R, Safary $E$, et al. (2021) Knowledge, experience and perception of gender-based violence health services: A mixed methods study on adolescent girls and young women in Tanzania. Int J Environ Res Public Health 18: 8575.

29. Kpozehouen A, Paraïso NM, Ahanhanzo YG, Klikpo $E$, Jérôme CS, et al. (2018) Perception of Beninese on intimate partner violence: Evidence from 2011-2012 Benin demographic health survey. BMC Women's Health 18: 140.

30. Abeya SG, Afework MF, Yalew AW (2012) Intimate partner violence against women in west Ethiopia: A qualitative study on attitudes, woman's response, and suggested measures as perceived by community members. Reproductive Health 9: 14. 